Purković, D. \& Kovačević, S. (2020). Teachers' perception of the influence of the teaching context on cognitive Achievements in general technology education, International Journal of Cognitive Research in Science, Engineering and Education (IJCRSEE), (8), Special issue of Current Research and Trends in Cognitive Sciences 2020, 1-15.

Original scientific paper

UDK:

Received: October, 09.2020.

Revised: November, 24.2020.

$371.12: 159.923 .3$

Accepted: December, 04.2020.

doi: 10.23947/2334-8496-2020-8-SI-1-15

\title{
Teachers' Perception of the Influence of the Teaching Context on Cognitive Achievements in General Technology Education
}

\author{
Damir Purković ${ }^{1 *}$, Stjepan Kovačević ${ }^{2}$ \\ ${ }^{1}$ Study of Polytechnics, University of Rijeka, Rijeka, Croatia, e-mail: damir@uniri.hr \\ ${ }^{2}$ Department of Polytechnics, Faculty of Science, University of Split, Split, Croatia, e-mail: stjepan@pmfst.hr
}

\begin{abstract}
High achievements in the cognitive domain are the ultimate goal of any education, within it is important to understand the role of the teaching context. In this regard, the purpose of this research was to determine how teachers perceive the role of the teaching context on the pupils' achievements in the cognitive domain in general technology education. For this purpose, a survey of teachers' perception towards the influence of isolated elements of the teaching context, specific to technology education, on the achievements of learning objectives was conducted. The study was conducted as a survey on a stratified sample of technology education teachers $(\mathrm{N}=194)$ from Croatia. ANOVA repeated measurements statistical procedure was used to process the research results. The analysis of the results showed that teachers give preference to certain contextual elements over others. These are activities with technological artifacts, models and simulations, service-learning activities, field trips, work in an appropriate space and the student's presentation of their own results. These elements can be considered as a contextual basis for the cognitive development of pupils in general technology education. Teachers' perception of the influence of other elements of the teaching context is not negligible, but obviously there is no priority over these elements, which is why further research is needed.
\end{abstract}

Keywords: teaching context, contextual approaches, elements of teaching context, cognitive achievements, technology education.

\section{Introduction}

For decades, contextual learning has been considered a successful way of achieving teaching goals, especially in science and technology education. The teaching context in which such teaching performs has an important and irreplaceable role. The teaching context can be described as a system of interior and exterior factors and conditions of human behavior and activity, which may affect perception, understanding and transformation of a particular situation, and which determine the meaning and sense of the situation as a whole and its comprising components (Verbitsky and Kalashnikov, 2012). From such a definition, it is clear that the learning context is related to situated learning theory, that is, that learning cannot be achieved or looked at separately from the context in which it occurs (Bell et al., 2013). The context can be viewed from a structural and functional (process) aspects. From a structural point of view, the context can be viewed as an imaginary multidimensional space in which different materials and communication situations are organized topologically and logically around a central object and give meaning to that object (Bateson, 1972; Verbitsky and Kalashnikov, 2013). The functional aspect refers to the relational understanding, as a mechanism that connects mental contents. Since information is the basis for understanding, it can be understood as a reflection of a certain impact on the recipient (here the student is meant), which implies a comparison of the previous and accompanying condition of the recipient (Stepansky, 2006). In other words, understanding any information that an individual receives cannot exist without context, because information can be perceived and understood only in the context of the individual's previous mental state (Purković, 2016). Therefore, the teaching context can be viewed from a structural and functional point of view. The structural aspect of the teaching context actually makes the connection of new teaching content with authentic and socially relevant knowledge. It is actually the tangible or visible (physically) part of the learning environment connected with the learning content. At the same time, the functional aspect integrates new content into a stimulating learning environment, which consists of social interactions and situations in which learning and teaching activities take place. The structural and functional aspects together should give the student the sense and meaning of the learning

"Corresponding author: damir@uniri.hr 
subject matter, and should ensure the student's understanding of the content they are learning, which is a priority of the teaching process. In doing so, students should be clear about what they need to achieve and should lead to the opportunity for different, performative behaviors, which is only possible in scenarios that include that content (Gardner, 1993; Biggs, 1996; Biggs et al., 2001). The existence of such a context can facilitate and secure the contextual learning process. Contextual learning Brown (1998) defines as a strategy for helping students construct knowledge and meaning of new information through a complex interaction of teaching methods, content, situations and time. Berns and Erickson (2001) see such learning as a concept that helps teachers establish subject-matter relations with real-life situations and motivates students to relate knowledge to application in their lives as family members, citizens, and workers, and to participate in the hard work that learning requires. Johnson (2002) presents contextual learning and teaching as a holistic system, that is, an educational process that aims to help students understand the meaning of the academic content they are learning, by combining it with the context of everyday life. That is to say, with the context of their personal, social, and cultural circumstances. The importance of contextual learning and teaching, as a concept that involves relating content to the context in which such content will be applied, has been pointed out by other researchers. (Petrina, 1992; Kelley and Kellam, 2009). Such linking of content to the meaningful context that should provide contextual learning and teaching should be achieved through specific contextual approaches to teaching. So contextual approaches are actually strategies or teaching procedures that will provide students with learning in an appropriate teaching context. In theoretical considerations, these approaches most often include problem-based learning, collaborative situational learning, project-based learning, service learning, and work-based learning, as teaching approaches that include context as a critical component (Putnam, 2001; Berns and Erickson. 2001; Purković and Bezjak, 2015). From the point of view of general technology education, Purković and Bezjak (2015) include in these approaches: a) project-based learning (and teaching), b) service learning activities, c) professional excursions (field trips), d) problem-based learning, and f) anchored instructions and g) isolated practical activities. Therefore, the teaching context should allow students to understand the content through contextual learning, while contextual approaches should provide appropriate teaching activities that support such learning.

Despite relative clear theoretical definitions of the teaching context, contextual learning, and contextual approaches to teaching, exploring the impact of such teaching on student achievement is fraught with problems. The biggest problem is the many performance differences in teaching policies and practice, including differences in technology education, where the real contextual approaches do not dominate. In such circumstances, contextual approaches have been explored, mainly as part of experimental researchadapted situations, which differ notably from the realities in which teaching is conducted. On the other hand, if the research deprived of such situations and carried out in realworld teaching conditions, then it is difficult to distinguish the influence of contextual teaching from the influences of other contextual factors outside school (parents, society, social and cultural environments, etc.). Therefore, it is often necessary to analyze such approaches and investigate the effects of partial elements or components of contextual approaches to teaching. Such difficulties are also present when researching the impact of contextual approaches in primary schools in Croatia, which includes general technology education. Specifically, general technology education in Croatia mainly realizes through the regular curriculum of the Technical Culture subject and through various extracurricular activities. The regular curriculum realized over only 35 hours per year, as a 90-minute class with the whole class every other week. Given the long-standing closed and traditionally oriented curriculum, teaching generally consists of simple individual activities (Teaching programmes for compulsory education, 2006). During the realization of the subject, pupils learn about technology (depending on the class) and carry out basic technical activities (e.g. design, production, assembly, testing, etc.) (Purković, Suman and Jelaska, 2020). Due to the limited duration, important elements of the contextual approach are missing, such as pupils' collaborative activities on the realization of their own ideas in a meaningful context. In a significantly different role are pupils attending extracurricular activities, which realized through an open or semi-open curriculum for two or more hours per week. However, even in such programs, the teacher-mentor often directly imposes students' projects and activities, while in very few cases activities are the fruit of the pupils' ideas. Such organization and realization of general technology education in Croatia clearly indicates that the impact of contextual approaches to teaching is not possible to research directly since such approaches generally do not exist in practice in the full sense of their meaning. Nevertheless, the different ways and forms of realization of technology education and the rich experiences and successes of teachers in the development of technical creativity (Malinar, 2008) speak in favour of the role and importance of the teaching context, regardless of the forms and approaches to teaching in a specific Croatian context. It is therefore worth exploring this impact on student achievement. However, such research presupposes an 
analytical approach, that is, the isolation of elements of the teaching context and contextual approaches to teaching in order to explore their impact on students' achievements and development (Purković, 2016). Given the key role in teaching, teachers' beliefs and attitudes also impose themselves as an important medium through which this impact can be explored.

Teachers' perception of the effectiveness of their own teaching is related to their knowledge but also related to their attitudes and beliefs. Teachers' beliefs and attitudes are closely related to their behavior and practice in the classroom (Nespor, 1987), and can be defined as a subset of a group of constructs to name, define, and describe the structure and content of mental states considered to guide the actions of a particular person (Richardson, 1996). Although the individual's attitudes and beliefs as a whole represent his or her personal understandings, beliefs, values, judgments, opinions, cognitions, prejudices, perceptions, preferences, personal theories, and similar constructs about a particular reality, they are scientifically relevant only if they are the product of cognition and experience in such reality. The construct of educational beliefs is broad and refined for research purposes into a number of specific sub-constructs (Pajares, 1992). These sub-constructs include beliefs about their own influence on the level of student achievement (teacher effectiveness), beliefs about the nature of knowledge (epistemological beliefs), beliefs about self-perception (own-concept), and beliefs about self-confidence in performing certain tasks (self-efficacy) (Albion, 1999). Given that, unlike knowledge, beliefs are based on assessment and judgment (Pajares, 1992), teachers' beliefs about effectiveness and self-efficacy in teaching are important in such research. Although teachers' beliefs can strongly influence their perception and be an unreliable guide to the nature of things, due to the connections between educational beliefs with planning, decisionmaking, and practice, they can be powerful predictors of teacher behavior and teaching success (Pajares, 1992; Albion, 1999; Archambault et al., 2012). The importance and influence of teacher perception on student achievement has its foundations in social-cognitive theory (Bandura, 1986) through the notion of self-efficacy. This specific situational construct tells how the very perception of teaching, if positive, can have a positive effect on achievement. Teachers with a strong sense of teaching effectiveness are more tolerant toward students' mistakes, strive to fight for student success, and are more willing to take the risks of implementing new strategies in teaching, because of reduced fear of failure (Knoblauh and Hoy, 2008). Research also shows that teachers' beliefs about student success are indeed related to student achievements (Abudu and Gbadamosi, 2014; Jordan, 2018; Ekperi et al., 2019), which contributes to the validity of this research as well. These researches show that teachers' beliefs and knowledge can be predictors of student success, and the role of teachers' evaluative thinking as support for assessment abilities has been recognized (Buckley et al., 2015; Schwandt, 2015). This term defined as critical thinking applied in the context of evaluation, motivated by an attitude of inquisitiveness and a belief in the value of evidence (Buckley et al., 2015). Studies of the impact of context on teaching and teacher beliefs have shown that context can significantly influence teachers' perceptions of performance, as well as the effect of teaching (Bandura, 1997; Goddard and Goddard, 2001; Jordan, 2014; Wardani et al., 2020). Despite such findings, context is not an area where primary consideration should be given to teacher effectiveness (Labone, 2004), but to teaching success. This brief review showed that an experienced teacher is the most competent internal evaluator and can reliably assess what can affect the success of teaching. Nevertheless, a teacher's perceptions should be viewed as his or her subjective perception rather than as a measurable magnitude of student achievement. In this sense, teacher perception may represent a certain limitation in the analysis of the results of such perceptions. This limitation does not diminish the value of the teacher's perception of the achievement of teaching objectives, as a real indicator of that achievement, but also as a result of the influence of various factors on this perception. In this sense, the relation between the teacher's perception and the success of teaching can be viewed as the influence of the teacher's perception on the teaching process, as the influence of different contextual (environmental) elements and factors on that perception, and as the influence of contextual elements and factors on the teaching process (Purković and Jelaska, 2014). Regardless of the point of view, the teacher's perception of what positively affects student achievement should be taken as a relevant indicator, which also applies to elements of the teaching context.

\section{Materials and Methods}

Due to the importance of the teaching context for student achievements and the importance of teachers' beliefs for teaching success, the main aim of this research is to find out how the teachers of Technical Culture perceive the importance of the specific elements of the teaching context to the students' achievements in the cognitive domain. This is important in order to scientifically substantiate the 
importance of the role of the teaching context in the process of developing students' cognitive abilities in technology. In this way, the aim is to influence the further development of the technology education curriculum in Croatia and beyond. Namely, the concept of knowledge in technology differs greatly from most other subjects and areas, which is why the process (path) of cognition itself differs (more in Purković, 2018). In this sense, it is important to shed light on what context in technology learning has priority, so that the curriculum can be optimized. Namely, lately there are tendencies that favour learning "by the book" and online learning of all subjects. At the same time, technological literacy is often reduced to information literacy. Such trends negatively affect the development of the curriculum, and thus the development of students. Given the importance of teachers in the teaching process, their perception of the teaching reality should be taken into account in the process of improving teaching. In this sense, the elements of the teaching context elected by the previous analysis of the elements of contextual approaches to technology education (Purković, 2016), while students' levels of the achievements are classified according to the structure of the dimensions of knowledge (Krathwohl, 2002). The isolated elements of the teaching context were:

- Conducting professional excursions (field trips),

- Activities in student cooperatives, camps, gardens and workshops (service learning activities),

- Activities in a suitable space (workshop, laboratory, computer classroom, etc.),

- Use of models and simulations (3D models of machines, software simulations, etc.)

- Use of video materials and films (know-how videos, technological macro-context films, etc.)

- Use of photographs, pictures, drawings and schemes during the activity,

- Use of books, textbooks, magazines and texts (reading, working on a text, solving tasks, etc.)

- Activities with customized learning materials (mental maps, self-assessment materials etc.)

- Use of technical documentation (drawings, plans, technological lists etc.)

- Use of computers and ICT within activities (drawing, programming, digital content creation, etc.),

- Activities with artefacts of technology (materials, tools, machines, devices and instruments),

- Presentation of their own results (products, plans, solutions etc.)

The structure of dimensions of knowledge included: a) knowledge of subject content (factual knowledge); b) understanding of the content (conceptual knowledge); c) the application of knowledge (procedural knowledge); and d) managing one's own learning; and e) self-assessment of one's own knowledge as elements of the metacognitive dimension of knowledge. Factual knowledge is a basic element that students must know how to be familiar with a discipline or solve problems (Krathwohl, 2002), such as knowledge of terminology and specific details and elements. Conceptual knowledge is the interrelationships between the basic elements in a larger structure that allow them to function together. Here it is knowledge of the physical and functional nature of artefacts of technology, knowledge of the structure and principles of operations, classification and categorization of creations and technologies, understanding of graphic representations, etc. Procedural knowledge related to methods of inquiry, and criteria for using skills, algorithms, techniques and methods. Here it refers to knowledge of technology (know-how) and application of knowledge and skills for decision-making, design, manufacture and testing of creations and products. Learning self-regulation and knowledge self-assessment are part of the metacognitive dimension. This dimension represents knowledge of cognition in general as well as awareness and knowledge of one's own cognition, and include strategic knowledge, knowledge about cognitive tasks, and self-knowledge. Here, this includes the pupil's awareness of one's own knowledge and abilities, i.e., the ability to assess one's own knowledge, and discover one's own ways to achieve learning success.

Teachers' perceptions of the effect of isolated elements of the teaching context and contextual approaches on achievement were examined by an internet questionnaire. Questionnaire management, communication with teachers, and initial processing of results were conducted using an open source system Limesurvey. The data collected through the KONTK (KONtekst Tehničke Kulture) instrument, was previously validated and used in a comprehensive study of the impact of the teaching context on the achievement of the goals of teaching Technical Culture (Purković, 2016). For the purposes of this research, the questionnaire was reduced to examine the perception of the effects of teaching context elements on achievements in the cognitive domain. Therefore, the questionnaire covered teachers' beliefs about the effect of selected elements and approaches on pupils' knowledge of teaching content (KNOW), content understanding (UNDR), application of knowledge (APPK), self-regulated learning (SREG), and self-assessment of their own knowledge (SEVA). Teachers responded to the posted effect statements based on a scale of Likert-type assessments ranging from 1 to 5 , with 1 indicating the smallest and 5 the largest effect on student achievement. Elements of the teaching context and contextual approaches to teaching were extracted based on an analysis conducted by Purković (2016), which included 12 elements 
of the teaching context specific to the Croatian educational environment. These elements include pupils activities in: conducting professional excursions (FTRP), working in student cooperatives, camps, gardens and workshops (SELE), activities in appropriate space (ASPA), use of models, models and simulations (MSIM), use of videos and films (VIMA), use of photographs, images, drawings and schemes (FPPS), use of books, textbooks, magazines and texts (LIBR), activities with customized learning materials (MATL), use of appropriate technical documentation (PLAN), use of computers and ICT (CICT), activities with artefacts of technology - materials, tools, machines, devices and instruments (TART), presentation of their own results (PRER).

The research was carried out on a proportional stratified sample $(N=194)$ of teachers of Technical Culture, as the Croatian version of general and compulsory technology education subject. The sample was selected according to the typical structure of the total population of technical culture teachers in Croatia (Purković and Ban, 2013; Purković and Jelaska, 2014; Purković, 2015; Purković, 2016). Accordingly, the sample of teachers consisted of $5 \%$ of teachers with less than 5 years of teaching experience, $15 \%$ of teachers with 5 to 10 years of experience, $45 \%$ of them with 10 to 20 years of experience, and $35 \%$ of teachers with more than 20 years of teaching experience. The sample was dominated by $55 \%$ of teachers with targeted teacher education, $35 \%$ of teachers with engineering education, while $10 \%$ of teachers had a different education or a lower level of education than provided for by existing legislation. Considering the total number of about 740 active technical culture teachers in the Republic of Croatia and the large proportion of teachers with years of teaching experience, the data obtained from such a sample of teachers can be considered a valid basis for generalization of the research results.

After collecting the data and eliminating incomplete answers, their computer processing and analysis was performed. Relevant values of descriptive statistics were calculated for all variables, while the results of the research showed only the most necessary ones, such as mean (M) and standard deviation (SD). Repeated measures ANOVA was used to determine the statistical significance of differences within teachers' assessments of the effect of contextual elements and approaches on individual student achievement in the cognitive domain. In this way, differences with the first type error $\alpha=0.05$ were identified and the squared partial eta (np2) was determined as a measure of the effect size. The limit values of this indicator were selected according to the limitations and guidelines for the application of this indicator (Cohen, 1973; 1992): $\eta$ 2 < 0.10 for low effect; $\eta$ 2 $<0.25$ for medium effect and $\eta p 2<0.40$ for high effect. For significant F-values, Bonferroni post-hoc tests were applied to identify statistically significant differences between effect assessments of contextual elements for each student achievement. All the results were interpreted qualitatively, thus distinguishing a group of contextual elements and approaches that, from a teacher's perspective, significantly influence the pupils' achievements in the cognitive domain in general technology education.

\section{Results}

For testing the appropriateness of distributions for estimates using ANOVA rm statistical procedure, descriptive statistical analysis was performed and baseline parameters were extracted (Table 1). The normality of the distributions was then examined and their sphericity was determined by Mauchly's test. The normality of the distribution was examined by Kolmogornov-Smirnov and Shapiro-Wilks tests, which established that most of the distributions from the datasets were normally distributed and suitable for such statistical processing. Exceptions related to the deviations of some distributions from the normal, due to the characteristics of the research sample, are not thought to significantly affect the results of the analysis (Harwell et al., 1992; Lix et al. 1996). Sphericity tests revealed the disturbed sphericity of distributions in all datasets, which is why the GG correction of degrees of freedom presented in Table 2 applied. 
Purković, D. \& Kovačević, S. (2020). Teachers' perception of the influence of the teaching context on cognitive Achievements in general technology education, International Journal of Cognitive Research in Science, Engineering and Education (IJCRSEE), (8), Special issue of Current Research and Trends in Cognitive Sciences 2020, 1-15.

Table 1

Basic parameters of descriptive statistics (M, SD) for the estimates of the effect of contextual elements on a pupils' achievements: knowledge of content (KNOW), content understanding (UNDR), knowledge application (APPK), ability of self-regulated learning (SREG), self-evaluation of achievements (SEVA).

\begin{tabular}{|c|c|c|c|c|c|c|c|c|c|c|}
\hline \multirow[t]{2}{*}{ Pupils activities at ... } & \multicolumn{2}{|c|}{$\begin{array}{l}\text { Knowledge } \\
\text { (KNOW) }\end{array}$} & \multicolumn{2}{|c|}{$\begin{array}{l}\text { Understanding } \\
\quad \text { (UNDR) }\end{array}$} & \multicolumn{2}{|c|}{$\begin{array}{c}\text { Applying } \\
\text { knowledge } \\
\text { (APPK) }\end{array}$} & \multicolumn{2}{|c|}{$\begin{array}{l}\text { Self-regulated } \\
\quad \text { (SREG) }\end{array}$} & \multicolumn{2}{|c|}{$\begin{array}{l}\text { Self-evaluation } \\
\text { (SEVA) }\end{array}$} \\
\hline & M & $S D$ & M & $S D$ & M & $S D$ & M & $S D$ & M & $S D$ \\
\hline $\begin{array}{l}\text { conducting a professional } \\
\text { excursion [FTRP] }\end{array}$ & 4.15 & 0.688 & 4.12 & 0.709 & 4.08 & 0.726 & 3.60 & 0.848 & 3.73 & 0.741 \\
\hline $\begin{array}{l}\text { Students' cooperative, } \\
\text { workshops... [SELE] }\end{array}$ & 4.22 & 0.709 & 4.24 & 0.664 & 4.45 & 0.611 & 3.97 & 0.730 & 4.11 & 0.666 \\
\hline $\begin{array}{l}\text { in appropriate spaces - } \\
\text { classrooms [ASPA] }\end{array}$ & 4.44 & 0.674 & 4.40 & 0.736 & 4.53 & 0.621 & 4.14 & 0.793 & 4.22 & 0.696 \\
\hline $\begin{array}{l}\text { activities with models and } \\
\text { simulations [MSIM] }\end{array}$ & 4.49 & 0.621 & 4.52 & 0.613 & 4.45 & 0.675 & 4.09 & 0.787 & 4.11 & 0.825 \\
\hline $\begin{array}{l}\text { use of video materials and } \\
\text { films [VIMA] }\end{array}$ & 4.08 & 0.757 & 4.02 & 0.798 & 3.86 & 0.852 & 3.49 & 0.967 & 3.41 & 0.973 \\
\hline $\begin{array}{l}\text { use photography, } \\
\text { pictures, schemes [FPPS] }\end{array}$ & 3.88 & 0.796 & 3.85 & 0.797 & 3.73 & 0.877 & 3.49 & 0.962 & 3.36 & 0.984 \\
\hline $\begin{array}{l}\text { activities with books, } \\
\text { journals, texts [LIBR] }\end{array}$ & 3.38 & 0.943 & 3.35 & 0.955 & 3.23 & 1.024 & 3.24 & 0.995 & 3.09 & 0.998 \\
\hline $\begin{array}{l}\text { activities with leaming } \\
\text { materials [MATL] }\end{array}$ & 3.86 & 0.795 & 3.89 & 0.764 & 3.81 & 0.891 & 3.66 & 0.891 & 3.66 & 0.926 \\
\hline $\begin{array}{l}\text { use of technical } \\
\text { documentation [PLAN] }\end{array}$ & 3.78 & 0.866 & 3.73 & 0.901 & 3.80 & 0.901 & 3.52 & 0.956 & 3.50 & 0.978 \\
\hline $\begin{array}{l}\text { activities with computers } \\
\text { and ICT [CICT] }\end{array}$ & 4.04 & 0.848 & 4.06 & 0.828 & 3.98 & 0.870 & 3.77 & 0.951 & 3.60 & 0.962 \\
\hline $\begin{array}{l}\text { activities with technology } \\
\text { artefacts [TART] }\end{array}$ & 4.54 & 0.691 & 4.59 & 0.647 & 4.67 & 0.647 & 4.21 & 0.801 & 4.41 & 0.716 \\
\hline $\begin{array}{l}\text { the pupil's presentation of } \\
\text { the activity [PRER] }\end{array}$ & 4.24 & 0.738 & 4.29 & 0.728 & 4.36 & 0.750 & 4.28 & 0.772 & 4.35 & 0.720 \\
\hline
\end{tabular}

From the basic data of descriptive statistics, it can be seen that teachers consider the activities with artefacts od technology (TART) to be the most effective for most students' achievements in the cognitive domain. The exception is the perception of the effect on self-regulated learning, for which teachers consider the presentation of pupils' own activities (PRER) to be the most effective element. Teachers rated the effect of student activities with books, textbooks, journals and text material (LIBR) as being the lowest on average. The data presented show the smallest deviations of the estimates for those elements that was the highest estimated. This group includes pupils' activities with artefacts (TART), professional excursions (FTRP), service learning activities (SELE), activities in appropriate space (ASPA), and activities with models and simulations (MSIM). This means that teachers largely agreed on the effect of these elements on students' cognitive achievement. On the other hand, estimates of the effect of the use of books, textbooks, journals and texts (LIBR), but also the use of technical documentation (PLAN), are the most varied, which indicates a higher dispersion of teaching perceptions about the use of these elements. Surprisingly, average estimates of using computers and ICT use (CICT) are significantly lower than expected, especially for higher levels of pupils' cognitive achievements. The presented results indicate the need for further analysis of the collected data. 
Purković, D. \& Kovačević, S. (2020). Teachers' perception of the influence of the teaching context on cognitive Achievements in general technology education, International Journal of Cognitive Research in Science, Engineering and Education (IJCRSEE), (8), Special issue of Current Research and Trends in Cognitive Sciences 2020, 1-15.

\section{Table 2}

Results of repeated measures ANOVA of the teachers' perceptions on pupils' achievements in cognitive domain: coefficient of correction of degrees of freedom $(\varepsilon G G)$, degrees of freedom with $G G$ correction (dfG-G), mean squared (MS), F-value (F), statistical significance (p), effect size (np 2).

\begin{tabular}{|c|c|c|c|c|c|c|}
\hline Pupils' achievements in the cognitive domain & $\varepsilon_{G-G}$ & $d f_{G-G}$ & MS & $F$ & $p$ & $\eta_{p}{ }^{2}$ \\
\hline Knowledge of teaching content [KNOW] & 0.704 & 7.774 & 30.540 & 53.377 & 0.000 & 0.217 \\
\hline Understanding teaching content [UNDR] & 0.714 & 7.855 & 33.941 & 55.567 & 0.000 & 0.224 \\
\hline Application of acquired knowledge [APPK] & 0.666 & 7.321 & 51.551 & 72.700 & 0.000 & 0.274 \\
\hline Self-regulated learning [SREG] & 0.718 & 7.902 & 31.191 & 46.405 & 0.000 & 0.194 \\
\hline $\begin{array}{l}\text { Self-assessment of one's own achievement } \\
\text { [SEVA] }\end{array}$ & 0.669 & 7.358 & 54.116 & 70.769 & 0.000 & 0.268 \\
\hline
\end{tabular}

Repeated measures ANOVA for each level of student achievement in the cognitive domain examined the statistical significance of differences within teachers 'assessment of the effect of contextual elements (Table 2). The analysis of the results reveals that the effect size, and therefore the significance of the differences, is highest for the data set associated with assessing the effect on students' applied knowledge $[F(7.321)=72.700, p<0.01, n p 2=0.274$, observed power $=1]$ and with the student's ability to self-assess achievements $[F(7.358)=70.769, p<0.01, \eta p 2=0.268$, observed power $=1]$. Slightly lower effect sizes, as well as significance differences, are made by assessments on the understanding of teaching content $[F(7.714)=55.567, \mathrm{p}<0.01, \mathrm{np} 2=0.224$, observed power $=1]$ and on the student's knowledge of teaching content $[F(7.704)=53.377, p<0.01, n p 2=0.217$, observed power $=1]$. The smallest effect size and significance of differences, although not less important, were observed for assessing the effect of elements of the teaching context on students' ability to manage their own learning $[F(7.718)=46.405, p$ $<0.01 ; n p 2=0.194$, observed power $=1$ ]. From these differences within the estimates, it is clear that the statistical significance of the differences, $F$ values and effect sizes are respectable. Therefore, it is worth further analysing the differences between assessing the effect of contextual elements and approaches on students' achievements. In order to isolate those contextual elements and approaches that, from a teacher's perspective, significantly influence student achievement in the cognitive domain, Bonferroni's post-hoc tests highlighted the differences between assessments of the effect perceptions for each level of achievements.

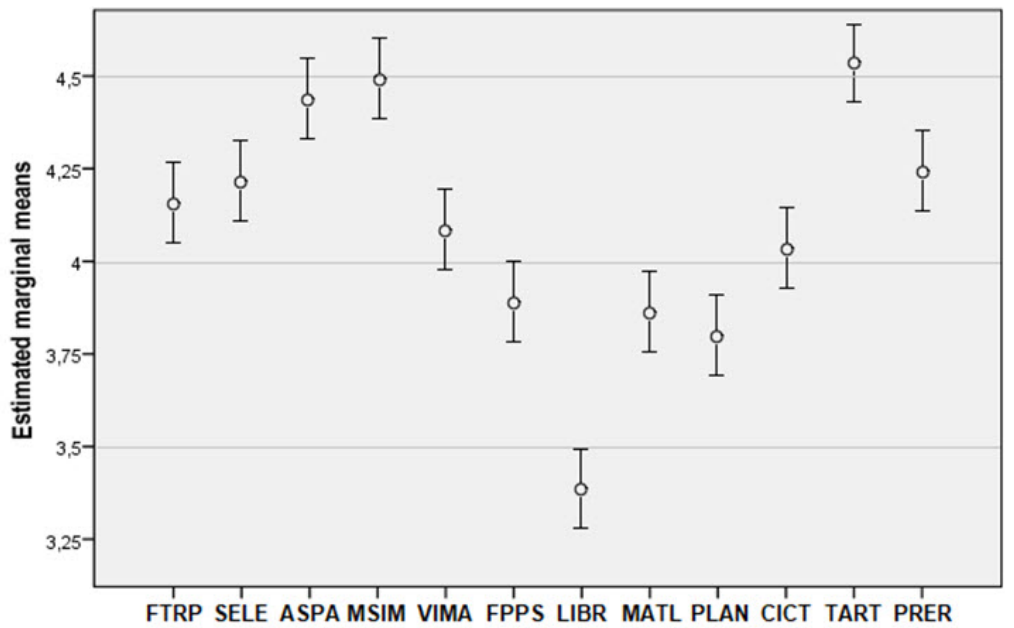

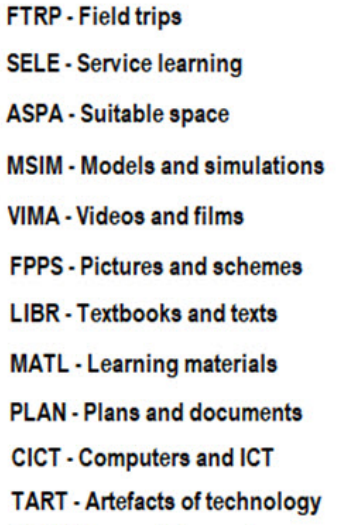

PRER - Presentations of own results

Figure 1. Estimates of the influence of contextual elements on pupils' knowledge

Among the assessments of the effect of contextual elements and the approach on students' knowledge, a group of elements that teachers consider the most important stand out (Figure 1). This group consists of student activities with artefacts of technology (TART), use of models and simulations (MSIM), and activities in appropriate spaces (ASPA), whose estimates are not statistically different but differ from the estimates of other elements at the level of statistical significance $p<0.05$. The group of elements whose assessments of the effect on students' knowledge that are not negligible include; the pupils' presentation of their own results (PRER), activities in pupils' cooperatives, camps, gardens and 
work-shops - service learning (SELE), professional excursions (FTRP) and the use of video material in teaching (VIMA). The values of the estimates of these elements do not differ significantly, however they differ from the lower estimated elements at the level of statistical significance $p<0.05$. An exception is the assessment of the use of computers and ICTs (CICT), which estimates are not significantly different from the estimates of the use of video materials in teaching (VIMA). However, due to the statistical significance of differences with respect to other elements in this group, use of computers and ICT (CICT) we can only cautiously classify as a part of this group. Elements whose effect is not highly estimated include the use of photographs, images, drawings and schemes (FPPS), the use of learning materials (MATL), and the use of technical documentation (PLAN), whose values of estimates differ from others at the statistical significance level $p<0.01$. The effect assessments of the lowest-scoring element, the use of books, textbooks, journals, and texts (LIBR) are different from other estimates at the level of statistical significance $p$ $<0.001$, making this element the least effective on pupils' knowledge.
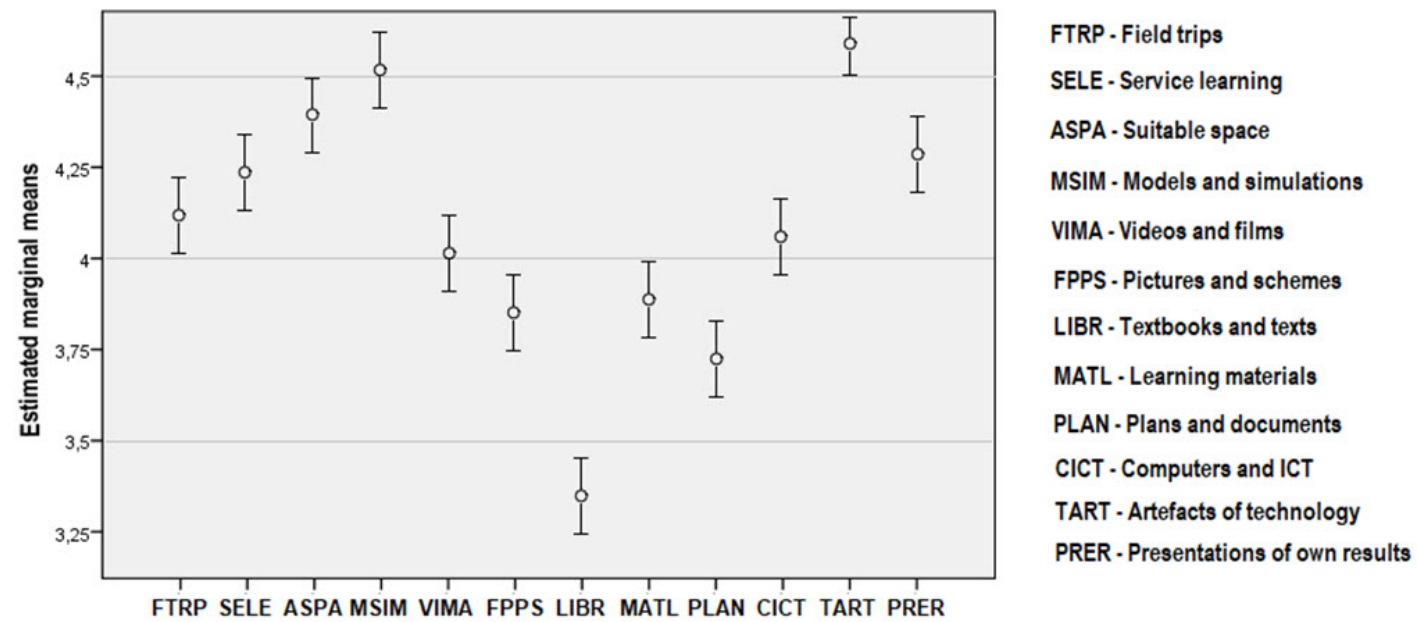

Figure 2. Estimates of the influence of contextual elements on pupils' understanding

In assessing the effect on pupils' understanding of content (Figure 2), teachers consider the most effective are the activities with artefacts of technology (TART), and the use of models and simulations in teaching (MMSI), whose assessment values differ from most others at the statistical significance level of $p<0.05$. The exception here is the assessments of effect of the activities in appropriate Space (ASPA), whose estimation values are not significantly different from using models and simulations (MSIM), which is why we can count this element as the part of the group with the highest effect. Somewhat lower, but still high, is the estimated effect of pupils' presentation of their own results (PRER), activities in student cooperatives, gardens, camps and workshops (SELE) and professional field trips (FTRP). The values of the estimates of these elements differ from those estimated lower at the level of statistical significance $p<0.05$. The exception is the implementation of professional excursions (FTRP), whose estimates do not differ significantly from the assessments of video material use (VIMA) and computer and ICT use (CICT), making the effect of these elements relatively influential for the content understanding. However, due to the absence of a statistically significant difference from the lower estimated effects of the use of photographs, images, drawings and schemes (FPPS) and activities with learning materials (MATL), the above elements can be included in the same effect group. Specifically, the values of estimates within this group do not differ from each other, and they differ from most of the others at the level of statistical significance $p<0.05$. Activities with technical documentation (PLAN) form a relatively separate element since the values of the estimates do not differ statistically significantly from the elements (FPPS) and (MATL) of the previous group, but differ from the lowest estimated effect of the use of textbooks, journals and texts (LIBR) at the level of statistical significance $p<0.001$. 


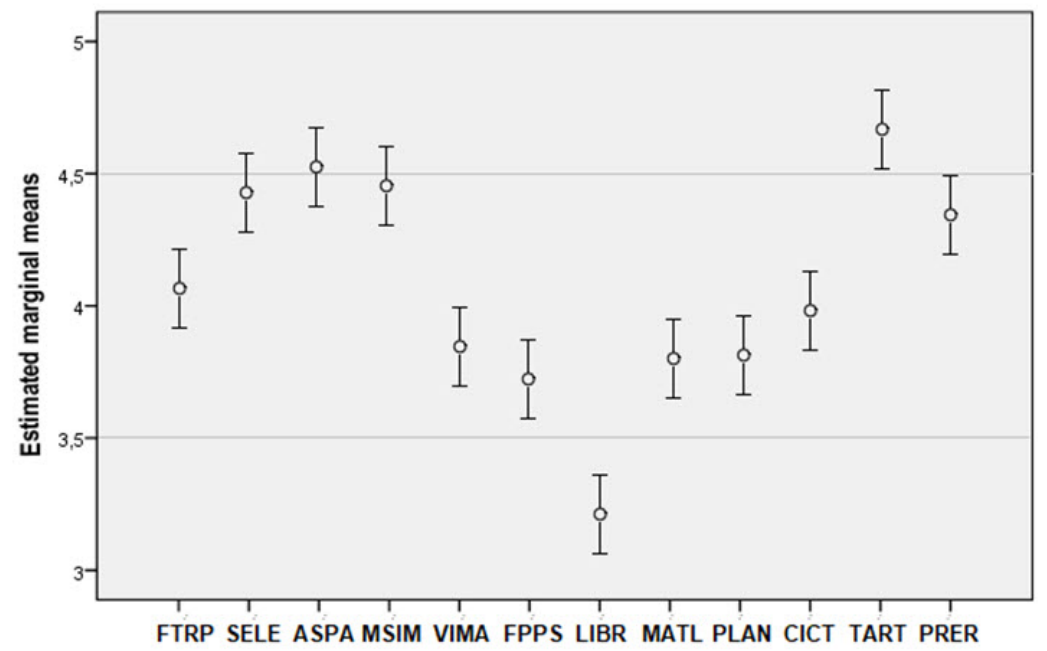

FTRP - Field trips

SELE - Service learning

ASPA - Suitable space

MSIM - Models and simulations

VIMA - Videos and films

FPPS - Pictures and schemes

LIBR - Textbooks and texts

MATL - Learning materials

PLAN - Plans and documents

CICT - Computers and ICT

TART - Artefacts of technology

PRER - Presentations of own results

Figure 3. Estimates of the influence of contextual elements on pupils' application of knowledge

When it comes to pupils' application of knowledge (Figure 3), teachers' estimates of student activity with artefacts of technology (TART) are by far the most significant and different from other estimates at the level of statistical significance $p<0.05$. An exception is the activities of students in a suitable space (ASPA) whose estimates are not statistically significantly different from the previous element. In the group of highly assessed elements, whose estimates differ from all lower ones at the level of statistical significance $p<0.01$, should be included already mentioned activities in the appropriate space (ASPA), activities with models and simulations (MSIM), service learning activities - cooperatives, gardens, workshops (SELE) and pupils' presentations of their own results (PRER). The group of elements whose influence on the application of knowledge is lower estimated consists OF professional excursions (FTRP), use of computers and ICT (CICT), use of video and film (VIMA), use of photographs, pictures, drawings and schemes (FPPS), activities with learning materials (MATL) and use of technical documentation (PLAN). The values of the estimates from this group do not differ statistically from one another, and they differ from other estimates at the level of statistical significance $p<0.001$. The lowest estimated influence was the use of books, journals and texts (LIBR), whose values of estimates differ from others at the level of statistical significance $p<0.001$.

When it comes to assessing the influence on pupils' self-evaluation abilities (Figure 4), the group of elements whose influence the teachers have highly evaluated are highlighted here: The highest estimated influence was the activity of pupils with artefacts of technology (TART), presentation of their own results (PRER), and the influence of activities in a suitable space (ASPA), activities in student cooperatives, gardens, camps and workshops (SELE) and the use of models and simulations (MSIM).The values of estimates from this group are not statistically different, but they differ from other estimates at the level of statistical significance $p<0.001$. The much lower-rated elements here include the estimates of professional excursions (FTRP), activities with computers and ICT (CICT), use of technical documentation (PLAN), activities with learning materials (MATL), use of videos (VIMA) and the use of images, drawings and photographs (FPPS). The values of the estimates of the elements in this group differ statistically from the other estimates at the level of statistical significance $p<0.01$. The effect of using textbooks, books, magazines and texts (LIBR) again rated lowest, with estimates differing from the others at the statistical significance level of $p<0.01$. 


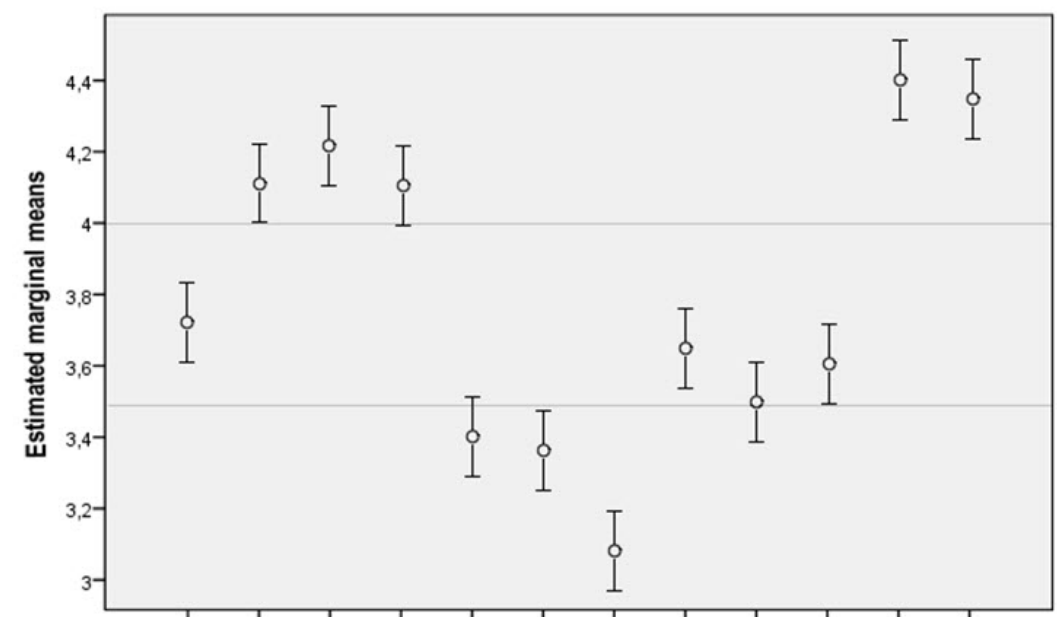

FTRP SELE ASPA MSIM VIMA FPPS LIBR MATL PLAN CICT TART PRER
FTRP - Field trips

SELE - Service learning

ASPA - Suitable space

MSIM - Models and simulations

VIMA - Videos and films

FPPS - Pictures and schemes

LIBR - Textbooks and texts

MATL - Learning materials

PLAN - Plans and documents

CICT - Computers and ICT

TART - Artefacts of technology

PRER - Presentations of own results

Figure 4. Estimates of the influence of contextual elements on pupils' self-evaluation abilities

Among the assessments of the influence of contextual elements and approaches on pupils' management of their own learning, the highest are the assessments of pupils' presentations (PRER), but also activities with artefacts of technology (TART), activities in a suitable space (ASPA), and the use of models and simulations in teaching (MSIM). The values of estimates from this group do not differ statistically from one another, but differ with respect to the lower estimated elements at the level of statistical significance $p<0.01$. An exception is the difference between the estimates of the last two elements (ASPA) and (MSIM) with respect to activities in student cooperatives, gardens, camps and workshops (SELE) according to which these estimates are not statistically significant. This finding places pupils' activities in student cooperatives, gardens, camps, and workshops (SELE) as important elements, yet are inferior to the highest-rated (PRER) and (TART) elements. Within the group of substantially lower assessments, consists the use of computers and ICT (CICT), learning materials activities (MATL), professional excursions (FTRP), use of photographs, pictures, drawings and schemes (FPPS), use of video materials (VIMA) and activities with technical documentation (PLAN). Specifically, the estimates of the elements in this group are generally not statistically different from one another, but differ from other elements at the level of statistical significance $p<0.05$. Nevertheless, it is worth noting that the estimates of activity with computers and ICT (CICT) in this group differ from the lower estimates (VIMA), (FPPS), (PLAN) at the level of statistical significance $p<0.05$. Such a finding means that the use of computers and ICT in teaching from a teacher's perspective has some influence on pupils' self-regulation of learning. Again, the lowest estimated influence is the use of books, journals and texts in teaching (LIBR), whose values of estimates differ from all others at the level of statistical significance $p<0.05$.

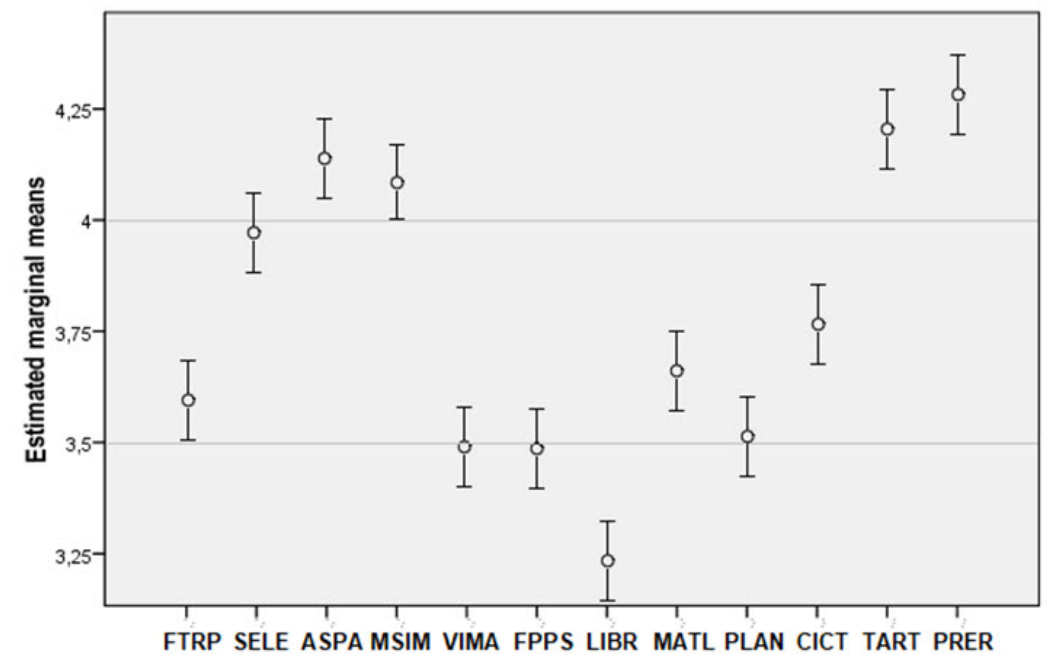

FTRP. Field trips

SELE - Service learning

ASPA - Suitable space

MSIM - Models and simulations

VIMA - Videos and films

FPPS - Pictures and schemes

LIBR - Textbooks and texts

MATL - Learning materials

PLAN - Plans and documents

CICT - Computers and ICT

TART - Artefacts of technology

PRER - Presentations of own results

Figure 5. Estimates of the influence of contextual elements on pupils' self-regulated learning 
Purković, D. \& Kovačević, S. (2020). Teachers' perception of the influence of the teaching context on cognitive Achievements in general technology education, International Journal of Cognitive Research in Science, Engineering and Education (IJCRSEE), (8), Special issue of Current Research and Trends in Cognitive Sciences 2020, 1-15.

\section{Discussions}

Within the teacher's assessments of the impact of contextual elements on the student's achievements in the cognitive domain, a certain hierarchical structure of the importance of these elements is recognized. Predictably, the greatest influence of context seen by teachers in the application of acquired knowledge and the pupils' abilities of self-assessment of their own achievements. Given the structure of the sample, which consists mainly of middle-aged teachers, it is certain that this hierarchy is not the result of "contemporary" educational trends. Moreover, it is opportune to assume that teachers base this judgment on personal experiences of the influence of the teaching context on the process, above all, of teaching and evaluating the level of student achievements. Precisely through the evaluation of procedural knowledge, but also the metacognitive skills of students, teachers can feel the "fine nuances" in the levels of student achievement, but also the role of the teaching context in these processes. It is expected that teachers are often not even aware of how certain interventions and innovations in the teaching process actually change the context, or elements of the teaching context. However, they are well aware of the results of that act. Especially if they result in better performance for students and are manifested in a real self-assessment of students' own achievements.

The pupil's factual knowledge and understanding of the teaching content are aspects of cognition that, according to teachers, can greatly influence the teaching context. Namely, the estimates of the impact of some contextual elements for these types of knowledge are slightly higher than the estimates for other types. Given that this knowledge represents lower levels of knowledge, this is logical and expected. Such an order represents the material-cognitive foundation of procedural (and meta-cognitive) knowledge and reflection of student achievements. However, in assessing these two, emphatically cognitive components of this domain, there is no real application of knowledge, and therefore the impact of the teaching context is more difficult to determine. Therefore, such a ranking of the impact of the teaching context would not be justified to interpret as the need to marginalize these types of knowledge and as an escape of teachers from traditional patterns of learning and teaching. Moreover, it seems that teachers, through assessing the impact of the teaching context, perceive and position teaching content more realistically than a large number of theorists and proponents of contemporary educational approaches.

Managing one's own learning is a cognitive aspect of student achievement where teachers see the least influence of the teaching context. However, it should be emphasized here that it is actually about the attitudes of teachers towards the impact of context on the pupil's management of their own learning. It is about assessing the most complex psychological processes in students, learning! Teachers actually cannot determine the actual impact of context on managing students' own learning. They only indirectly, probably again through the level of student achievements, evaluate the extent to which meaningful and realistic teaching of the technology influences the students' thinking strategies. In doing so, teachers believe that the influence of context in managing their own learning is significant, which is certainly true, but difficult to objectively validate.

The problem of isolating contextual elements that significantly affect students' cognitive achievements from the teacher's perspective is much more complex. The results as a whole indicate that for lower levels of achievement (knowledge and understanding) the differences in assessments are significantly smaller than the differences for applied knowledge and metacognitive skills. Already from the preliminary descriptive analyses, it has been suggested that the traditionally established elements of the context in the teaching and teaching of the Technical Culture are considered by teachers to be less effective in the sphere of the progression of student cognition. Given the number of respondents, and the current educational policy and implementation of the Technical Culture curriculum, this information is critical. In particular, influence assessments of the use of books, textbooks, journals and texts (LIBR), as well as the use of technical documentation (PLAN), are the lowest ranked elements of context in the prediction of cognitive development. The teaching practice of Technical Culture in Croatia shows that these are the dominant contextual patterns for the teaching and learning process. Additional analysis of data for these two variables determined a certain dispersion of results within the sample of respondents, which would be useful to investigate with additional analyzes. Nevertheless, the general view of teachers is that they have the least influence in all the cognitive achievements discussed here, even for the lowest levels of knowledge. Furthermore, the results show that the average assessments for using computers and ICT (CICT) in teaching are significantly lower than expected, especially for higher levels of cognitive achievement. This finding can be interpreted in several ways. One of them is certainly the animosity of teachers towards computers and ICT as teaching content, which has been the legitimate content of Technical Culture for almost two decades in Croatia. However, such content is not treated as a technology development tool, though it accounted for almost $20 \%$ of the total curriculum share, which is twice as 
much as most core technological content. The relatively low assessments of the impact of computers and ICT can be attributed to the informal forcing of this element of context in all fields of education, especially in technology education. While this is implied for this education, it also often leads to inappropriate virtualization of learning and teaching, thus learning about the context rather than within it. Ultimately, such an approach leads to learning about the technological environment, a diametrically opposite effect from the curriculum-determined educational intent of learning within the technological environment, in a realistic context. This is supported by the results of determining the influence on students' cognitive achievement for the students' activities with artefacts of technology (TART). Precisely, this element of context that teachers find most influential in the development of all levels of cognition, except for selfregulation (self-management) of their own learning. The activities of pupils with technological artifacts represent the real context of the natural, social and technological environment and their interaction. Even without additional scientific studies, it is clear that activities with technological artifacts should be the basis for materializing the educational goals of technology teaching at all levels of education. Unfortunately, it is not the case, even at the highest levels of educational policies. Such results are broadly in line with previous research into teachers' perceptions of the impact of elements of the teaching context on the achievement of teaching goals (Purković, 2016), in which the activities of students with artefacts of technology have also been a dominant element of influence. After all, scientists agree that artefacts of technology, by their physical and functional nature, are the most direct way for a student's first understanding of technology (Mitcham, 1994; De Vries, 2016; Jones et al., 2013; Purković, 2018). However, it should emphasize that any educational reform and curricular approach, in addition to formal, declarative and cosmetic changes, also completely redefine the role of the teacher. Thus, the responsibility for the elements of context that will potentially result in cognitive student progression is borne by the teacher at all levels considered here.

In the opinion of teachers at almost all levels in the cognitive domain, except for self-regulated learning, important elements of context are pupils' activities with artefacts of technology (TART), field trips (FTRP), service-learning activities (SELE), activities in a suitable space (ASPA) and activities with models and simulations (MSIM). Although the impact of computer and ICT activities (CICT) is moderately assessed, today it forms an integrative "fabric" of technological literacy development and should be associated with important elements of the context. All of these elements actually complement the context of students' activities with artefacts of technology and are largely constrained by technological reality and the immediate environment. It should be noted that all significant elements of the context, apart from the responsibilities (and competences) of teachers as human resources, also require material resources, from appropriate space needs, teaching resources and aids to the financial resources for organizing and conducting field trips.

For pupils' self-regulation of their own learning, which also means the development of metacognition, teachers most assessed the impact of pupils' presentation of their own activity results (PRER). With the highly appreciated impact of activities with artefacts for this level of cognition, it is evident that teachers consider it important to invest a great deal of mental effort on the part of students to elaborate their own activities, especially with artefacts of technology. Given that pupils necessarily collaborate with each other in the process of preparing a presentation, by exploring sources and arguments, it can be observed that teachers understand the importance of the human aspect of technology for the development of pupil cognition.

\section{Conclusions}

The teaching context proves to be an important factor, but also a predictor of the success of each teaching, and especially of the technology education. However, given the permanently limited school conditions, the influence of contextual learning and teaching is not easy to explore. Therefore, analysis of the teaching context, which can be relevant to the learning process, is often the only "path" of research, and teachers are often the only "litmus" to determine which elements of teaching context can influence student achievements in the cognitive domain.

The teacher's perception of the influence of elements of the teaching context and approaches specific to general technology education clearly emphasizes the importance and hierarchical structure of the importance of those elements and approaches that should dominate this teaching. Pupils' activities with artefacts of technology (tools, machines, devices and instruments) are considered essential in technology teaching, and according to teachers, they have the greatest influence on content knowledge, content understanding and application of knowledge. Here, of course, it must be assumed that such activities are meaningful to the content that is learned from the pupil's perspective. In addition to activities with artefacts 
of technology, for developing pupils' self-regulated learning and self-assessment of their own learning, as part of metacognition, teachers emphasize the importance of pupil's presentation of the results of their own activities. At the same time, for each level of achievement in the cognitive domain, teachers highly rate the importance of student activities with models and simulations, service-learning activities, and the implementation of all activities in a space appropriate for technology education. Adding to these elements and high estimates of the influence of field-trips on achievements in the cognitive domain, a set of teaching context elements obtained as a set of dominant contextual activities in general technology education. Of course, activities with computers and ICT, although moderately influential, are imposed as an unavoidable element of the context, but without a decisive influence on the cognitive achievements of pupils. All other elements of the teaching context observed, which are common in almost all classes, from the teacher's point of view, are merely a means of contextualizing teaching content in general technology education and are not the basis for students' cognitive development. This highlights the fact that the process ("path") to technological knowledge is important for achieving a high level of student achievement and cannot be skipped by "serving knowledge" that abounds in books and the Internet. Therefore, these findings are an important step towards optimizing the general technology education curriculum in which certain context elements should take precedence over others.

Despite such findings, it should be emphasized that it is a teacher's perception of influence, rather than a real measurement of the impact of certain activities on student achievements. At the same time, it should be noted that no element of the context was considered unimportant by teachers, which is why all elements have a certain importance and significance for student achievement. Although the teacher is an important factor in the quality of teaching and can best assess what may have an impact on students in a particular teaching, here is elaborated a general perception that cannot be applied to every student and in every environment. Therefore, future research into the impact of the teaching context should explore how the achievements of students who have been intensively exposed to these dominant activities are distinguished. It is also necessary to investigate the impact of all elements of the teaching context on different brains, in order to gain a clearer insight into how students conceptualize technology in their own minds with respect to their individual differences. This will give a "clearer picture" of the real impact of the teaching context on the group and individual pupil achievements, which may shape the best structure of the learning and teaching context, as well as the future curriculums of general technology education.

\section{Acknowledgments}

We would like to thanks all the teachers of Technical Culture in Croatia who agreed to participate in this research and creation of this paper. We also thank the Croatian Education and Teacher Training Agency and the Croatian Association of Teachers of Technical Culture who animated teachers and were often crucial support in conducting our research.

\section{Conflict of interests}

The authors declare no conflict of interest.

\section{References}

Abudu, K. A., \& Gbadamosi, M. R. (2014). Relationship between teacher's attitude and student's academic achievemnt in senior secondary school chemistry. A case study of ljebu-Ode and Odogbolu Local Government Area of Ogun state. Wudpecker Journal of Educational Research, 3(3), 035-043.

Albion, P. R. (1999). Self-efficacy beliefs as an indicator of teachers' preparedness for teaching with technology. In Society for Information Technology \& Teacher Education International Conference (pp. 1602-1608). Association for the Advancement of Computing in Education (AACE). Retrieved from https://www.learntechlib.org/primary/p/8156/

Archambault, I., Janosz, M., \& Chouinard, R. (2012). Teacher beliefs as predictors of adolescents' cognitive engagement and achievement in mathematics. The Journal of educational research, 105(5), 319-328. https://doi.org/10.1080/0022067 1.2011.629694

Ashton, P. T., \& Webb, R. B. (1986). Making a difference: Teachers' sense of efficacy and student achievement. Longman Publishing Group.

Bandura, A. (1986). Social foundations of thought and action. Englewood Cliffs, NJ, 1986, 23-28.

Bandura, A. (1997). Self efficacy: The exercise of control, New York: Freeman.

Bateson, G. (1972). Steps to an ecology of mind. Northvale, NJ: Jason Aronson.

Bell, R. L., Maeng, J. L., \& Binns, I. C. (2013). Learning in context: Technology integration in a teacher preparation program informed by situated learning theory. Journal of Research in Science Teaching, 50(3), 348-379.

Berns, R. G., \& Erickson, P. M. (2001). Contextual teaching and learning: Preparing students for the new economy (Vol. 5). Columbus: National Dissemination Center for Career and Technical Education. 
Purković, D. \& Kovačević, S. (2020). Teachers' perception of the influence of the teaching context on cognitive Achievements in general technology education, International Journal of Cognitive Research in Science, Engineering and Education (IJCRSEE), (8), Special issue of Current Research and Trends in Cognitive Sciences 2020, 1-15.

Biggs, J. (1996). Enhancing teaching through constructive alignment. Higher education, 32(3), 347-364.

Biggs, J., Kember, D., \& Leung, D. Y. (2001). The revised two-actor study process questionnaire: R-SPQ-2F. British journal of educational psychology, 71(1), 133-149.

Brown, B. L. (1998). Aplying Constructivism in Vocational and Career Education, Information Series no. 378. Columbus: ERIC Clearinghouse on Adult, Career, and Vocational Education, Center on Education and Training for Employment, the Ohio State University. Retrieved from https://files.eric.ed.gov/fulltext/ED428298.pdf

Buckley, J., Archibald, T., Hargraves, M., \& Trochim, W. M. (2015). Defining and teaching evaluative thinking: Insights from research on critical thinking. American Journal of Evaluation, 36(3), 375-388. https://doi.org/10.1177/109821405581706

Cohen, J. (1973). Eta-Squared and Partial Eta-Squared in Fixed Factor Anova Designs. Educational and Psychological Measurement, 33, 107-112, https://doi.org/10.1177/001316447303300111

Cohen, J. (1992). A Power Primer. Psychological Bulletin, 112(1), 155-159.

De Vries, M. J. (2016). Teaching about technology: An introduction to the philosophy of technology for non-philosophers. Springer. Retrieved from https://link.springer.com/book/10.1007\%2F978-3-319-32945-1

Ekperi, P., Onwuka, U., \& Nyejirime, W. (2019). Teachers' Attitude as a Correlate of Students' Academic Performance. International Journal of Research and Innovation in Social Science (IJRISS), 3(1), 205-209.

Gardner, H. (1993). Frames of Mind: The Theory of Multiple Intelligences. NY: BasicBooks.

Goddard, R. D., \& Goddard, Y. L. (2001). A multilevel analysis of the relationship between teacher and collective efficacy in urban schools. Teaching and Teacher Education, 17(7), 807-818. https://doi.org/10.1016/S0742-051X(01)00032-4

Harwell, M. R., Rubinstein, E. N., Hayes, W. S., \& Olds, C. C. (1992). Summarizing Monte Carlo results in methodological research: The one-and two-factor fixed effects ANOVA cases. Journal of educational statistics, 17(4), 315-339. https:// doi.org/10.3102/10769986017004315

Johnson, E. B. (2002). Contextual teaching and learning: What it is and why it's here to stay. Thousand Oaks, CA: Corwin Press, INC

Jones, A., Buntting, C., \& de Vries, M. J. (2013). The developing field of technology education: A review to look forward. International Journal of Technology and Design Education, 23(2), 191-212. https://doi.org/10.1007/s10798-011-9174-4

Jordan, A. (2018). The supporting effective teaching project: 1 . Factors influencing student success in inclusive elementary classrooms. Exceptionality Education International, 28(3), 10-27. https://doi.org/10.5206/eei.v28i3.7769

Kelley, T. R., \& Kellam, N. (2009). A theoretical framework to guide the re-engineering of technology education. Journal of Technology Education, 20(2), 37. Retrieved from https://digitalcommons.usu.edu/ncete_publications/33/

Knoblauch, D., \& Hoy, A. W. (2008). Maybe I can teach those kids." The influence of contextual factors on student teachers' efficacy beliefs. Teaching and Teacher Education, 24(1), 166-179. https://doi.org/10.1016/j.tate.2007.05.005

Krathwohl, D. R. (2002). A revision of Bloom's taxonomy: An overview. Theory into practice, 41(4), 212-218. https://doi. org/10.1207/s15430421tip4104_2

Labone, E. (2004). Teacher efficacy: Maturing the construct through research in alternative paradigms. Teaching and teacher education, 20(4), 341-359. https://doi.org/10.1016/j.tate.2004.02.013

Lix, L. M., Keselman, J. C., \& Keselman, H. J. (1996). Consequences of assumption violations revisited: A quantitative review of alternatives to the one-way analysis of variance $\mathrm{F}$ test. Review of educational research, 66(4), 579-619. https://doi. org/10.3102/00346543066004579

Malinar, J. B. (2008). Nastava tehničke kulture u osnovnim školama Hrvatske [Teaching technical culture in primary schools in Croatia]. In D. Labaš (Ed.), 40 godina zajedno: i pola stoljeća nastave tehničke kulture u našim osnovnim školama (pp 59-86). Zagreb: Hrvatski savez pedagoga tehničke kulture.

Mitcham, C. (1994). Thinking through technology: The path between engineering and philosophy. University of Chicago Press. MSES/MZOS. (2006). Teaching programmes for compulsory education (pp. 304-309)

Nespor, J. (1987). The role of beliefs in the practice of teaching. Journal of curriculum studies, 19(4), 317-328. https://doi. org/10.1080/0022027870190403

Pajares, M. F. (1992). Teachers' beliefs and educational research: Cleaning up a messy construct. Review of educational research, 62(3), 307-332. https://doi.org/10.3102/00346543062003307

Petrina, S. (1992). Curriculum change in technology education: a theoretical perspective on personal relevance curriculum designs. Journal of Technology Education, 3(2), 37-47. https://doi.org/10.21061/jte.v3i2.a.5

Purković, D., \& Ban, E. (2013). Odnos formalnih kvalifikacija nastavnika i percepcije postignuća u nastavi tehničke culture [The Relationship of Formal Qualification of Teachers and Perception of Achievement in Teaching Technical Education]. Život i škola: časopis za teoriju i praksu odgoja i obrazovanja, 59(29), 223-238. Retrieved from https://core.ac.uk/ download/pdf/20340117.pdf

Purković, D. (2015). Realiteti tehničke kulture (Realities of Technical Culture). Rijeka: Faculty of Humanities and Social Sciences (e-book), Retrieved from http://www.ffri.uniri.hr/files/izdavacka/D_Purkovic-Realiteti_TK.pdf

Purković, D., Bezjak, J. (2015). Kontekstualni pristup učenju i poučavanju u nastavi temeljnog tehničkog odgoja i obrazovanja [Contextual approach to learning and teaching in the teaching of basic technical education]. Skolski vijesnik, 64(1), 131-152. Retrieved from http://skolskivjesnik.ffst.hr/wp-content/uploads/2020/08/2015_7_PURKOVIC_BEZJEK.pdf

Purković, D., \& Jelaska, I. (2014). The impact of selected contextual factors on the teachers' perception of the achievement of goals and objectives in teaching technical culture. Croatian Journal of Education: Hrvatski časopis za odgoj $i$ obrazovanje, 16(4), 977-997. Retrieved from https://cje2.ufzg.hr/ojs/index.php/CJOE/article/view/644

Purković, D. (2016). The elements of contextual learning and teaching approaches as factors of success of teaching technical culture. Doctoral thesis. University of Split, Faculty of Science, Retrieved from https://dr.nsk.hr/islandora/object/ pmfst $\% 3$ A536

Purković, D. (2018). Conceptualization of technology as a curriculum framework of technology education. In Proceedings TIE 2018. University of Kragujevac, Faculty of Technical Sciences Čačak, Serbia. Retrieved from https://bib.irb.hr/ datoteka/940081.P1.pdf

Purković, D., Suman, D., \& Jelaska, I. (2020). Age and gender differences between pupils' preferences in teaching general and compulsory technology education in Croatia. International journal of technology and design education. https://doi. org/10.1007/s10798-020-09586-x 
Purković, D. \& Kovačević, S. (2020). Teachers' perception of the influence of the teaching context on cognitive Achievements in general technology education, International Journal of Cognitive Research in Science, Engineering and Education (IJCRSEE), (8), Special issue of Current Research and Trends in Cognitive Sciences 2020, 1-15.

Purković, D., \& Kovačević, S. (2020). Hierarchical structure of the importance of teaching context in general technology education. Knowledge International Journal, 40(2), 317-325. Retrieved from https://ikm.mk/ojs/index.php/KIJ/article/ view/3900

Putnam, A. R., (2001). Problem-Based Teaching and Learning in Technology Education. Retriever from http://files.eric.ed.gov/ fulltext/ED465039.pdf

Richardson, V. (1996). The role of attitudes and beliefs in learning to teach. In Sikula, J., Buttery T. J. \& Guyton, E. (Eds.), Handbook of research on teacher education (2nd ed.), 102-119, New York: Simon \& Schuster Macmillan.

Schwandt, T. (2015). Evaluation foundations revisited: Cultivating a life of the mind for practice. Stanford University Press.

Stepansky, V. I. (2006). Psihoinformatsiya. Teoriya. Experiment [Psychoinformation. Theory. Experiment]. Moscow: Moscowskij psihologo-sotsialnyj institut.

Verbitsky A. A., \& Kalashnikov V. G. (2012). Category of "Context" and Contextual Approach in Psychology. Psychology in Russia, State of the Art, 5, 117-130.

Verbitsky, A. A., \& Kalashnikov, V. G. (2013). Contextual approach in psychology. European Scientific Journal, 9(32). Retrieved from http://citeseerx.ist.psu.edu/viewdoc/download?doi=10.1.1.896.9759\&rep=rep1\&type=pdf

Wardani, N. F. K., Sunardi, S. \& Suharno, S. (2020). Context-Based Thematic Teaching Materials to Improve Elementary Students' Learning Achievements. Jurnal Pendidikan Indonesia (JPI), 9(2), 193-202, https://doi.org/10.23887/jpiundiksha.v9i2.22822 
Purković, D. \& Kovačević, S. (2020). Teachers' perception of the influence of the teaching context on cognitive Achievements in general technology education, International Journal of Cognitive Research in Science, Engineering and Education (IJCRSEE), (8), Special issue of Current Research and Trends in Cognitive Sciences 2020, 1-15. 